\title{
SINTESIS METIL EUGENOL DAN BENZIL EUGENOL DARI MINYAK DAUN CENGKEH
}

\author{
Ngadiwiyana, Ismiyarto \\ Laboratorium Kimia Organik, Jurusan Kimia \\ Fakultas Matematika Dan Ilmu Pengetahuan Alam UNDIP \\ J1. Prof. Soedarto, SH Kampus Tembalang, Semarang 50275
}

\begin{abstract}
ABSTRAK
Eugenol merupakan komponen utama minyak daun cengkeh dan biasa digunakan sebagai obat sakit gigi, demam dan penyusun minyak wangi. Pengembangan eugenol mulai banyak dilakukan, khususnya membuat senyawa turunannya. Salah satunya dengan melakukan reaksi alkilasi terhadap gugus hidroksil. Dalam penelitian ini, alkilasi eugenol dilakukan melalui dua tahap yaitu dengan membuat garam eugenolat melalui reaks antara eugenol dengan $\mathrm{NaOH}$ dan dilanjutkan reaksi garam eugenolat dengan metil iodida dan benzil klorida. Hasil-hasil reaksi dipisahkan dan dianalisis menggunakan spektroskopi IR dan kromatografi gas-spektroskopi massa. Hasil reaksi berupa larutan berwarna kuning dengan rendemen metileugenol dan benzileugenol masing-masing 53\% dan 47\%.
\end{abstract}

Kata kunci: eugenol, alkilasi

\section{ALKYLATION OF EUGENOL AND ITS ACTIVITY EVALUATION AS FEROMON}

\begin{abstract}
Eugenol has widely used as analgesic and constituent of perfume. Research of eugenol has been occurred especially on developing of its derivates, one of the derivates is methyleugenol that has been reported as sex appeal for Bactrocera dorsalis. Based on this information, this reseach is proposed to develop the syntesis of its derivates with other alkylation agent to prove wetter the product can be used as feromon. The process of alkylation has been done with two steps; reaction of eugenol and $\mathrm{NaOH}$ to produce Na-eugenolat, followed by alkylation process with methyl iodide and benzyl chloride. Result was analized by spectroscopy IR and mass spectroscopy. Products of reaction are yellowish liquid of methyleugenol with rendemen $53 \%$ and benzyleugenol $47 \%$. Infra red spectra indicate the fungtional groups that belongs of them, mass spectroscopy record $\mathrm{m} / \mathrm{z}=178$ which relative moleculer weight of methyleugenol and $\mathrm{m} / \mathrm{z}=254$ which relative moleculer weight of benzyleugenol.activity
\end{abstract}

Key words: eugenol, alkylation

\section{PENDAHULUHAN}

Indonesia merupakan negara penghasil minyak atsiri terkenal di dunia, salah satu minyak atsiri yang banyak diproduksi di Indonesia adalah minyak cengkeh. Minyak cengkeh diperoleh secara mudah dari hasil penyulingan dengan sistem uap, baik terhadap daun, bunga maupun batangnya.

Komponen utama penyusun minyak atsiri pada cengkeh adalah eugenol. Senyawa ini telah lama digunakan masyarakat sebagai obat sakit gigi, demam dan berbagai keperluan medik lainnya. Selain itu senyawa ini telah dikembangkan juga sebagai komponen penyusun minyak wangi
(Austin, 1978) dan digunakan juga sebagai antioksidan (Sohilait, 2002).

Penelitian dengan material awal eugenol mulai banyak dilakukan, khususnya untuk sintesis senyawa derivate atau senyawa turunannya, misalnya eugenol dapat ditransformasi menjadi vanillin, sedangkan metileugenol sebagai feromon lalat buah (Bactrocera dorsalis) disintesis melalui metilasi eugenol (Vargas, et.al., 2000).

\section{METODE PENELITIAN}

Untuk mencapai tujuan penelitian di atas maka variable penelitian yang merupakan obyek 
penelitian adalah reaksi alkilasi eugenol melalui tahapan-tahapan kerja sebagai berikut:

\section{Sintesis metileugenol dari eugenol.}

Eugenol sebanyak $12,15 \mathrm{~g} \quad(0,074 \mathrm{~mol})$ dimasukkan dalam labu leher tiga $100 \mathrm{~mL}$ yang telah dilengkapi dengan corong penetes, pendingin (kondensor), termometer dan pengaduk magnet. Setelah itu ditambahkan 3,6 g $(0,090 \mathrm{~mol}) \mathrm{NaOH}$ dan campuran diaduk, melalui corong penetes dimasukkan $0,090 \mathrm{~mol}$ agen pengalkilasi metil iodida dan dimasukkan dalam labu leher tiga tetes demi tetes selama 1 jam, dengan pengadukan terus menerus. Campuran kemudian direfluks selama 2 jam untuk menyempurnakan reaksi, hasilnya didinginkan dan diencerkan dalam $25 \mathrm{~mL}$ akuades sehingga terbentuk dua lapisan. Lapisan bawah kemudian diekstraksi dengan $3 \times 5 \mathrm{~mL}$ eter. Lapisan atas dari semua hasil ekstraksi kemudian dicuci dengan akuades sampai netral selanjutnya dikeringkan dengan $\mathrm{Na}_{2} \mathrm{SO}_{4}$ anhidrat dan disaring. Ekstrak non polar ini dievaporasi, sehingga diperoleh larutan pekat berwarna kuning. Identifikasi komponen dilakukan dengan spektroskopi infra merah (FT-IR) dan GC-MS

\section{Sintesis benzileugenol dari eugenol.}

Eugenol sebanyak $12,15 \quad \mathrm{~g} \quad(0,074 \quad \mathrm{~mol})$ dimasukkan dalam labu leher tiga $100 \mathrm{~mL}$ yang telah dilengkapi dengan corong penetes, pendingin (kondensor), termometer dan pengaduk magnet. Setelah itu ditambahkan 3,6 g $\mathrm{NaOH}(0,090$ mol) dan campuran diaduk, melalui corong penetes dimasukkan 0,090 mol agen pengalkilasi benzil klorida dan dimasukkan dalam labu leher tiga tetes demi tetes selama 1 jam, dengan pengadukan terus menerus. Campuran kemudian direfluks selama 2 jam untuk menyempurnakan reaksi, hasilnya didinginkan dan diencerkan dalam $25 \mathrm{~mL}$ akuades sehingga terbentuk dua lapisan. Lapisan bawah kemudian diekstraksi dengan $3 \times 5 \mathrm{~mL}$ eter. Lapisan atas dari semua hasil ekstraksi kemudian dicuci dengan akuades sampai netral selanjutnya dikeringkan dengan $\mathrm{Na}_{2} \mathrm{SO}_{4}$ anhidrat dan disaring. Ekstrak non polar ini dievaporasi, sehingga diperoleh larutan pekat berwarna coklat kehitaman. Identifikasi komponen dilakukan dengan spektroskopi infra merah (FTIR) dan GC-MS.

\section{HASIL DAN PEMBAHASAN}

\section{Sintesis Metileugenol}

Telah dilakukan reaksi sintesis metil eugenol dari eugenol dan metil iodide dengan metode sintesis eter Williamson.

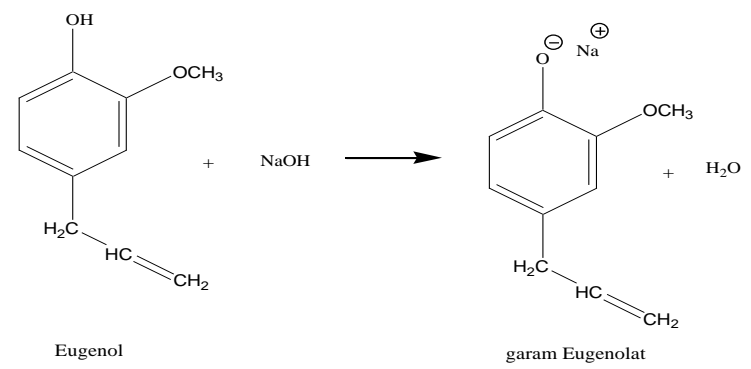

Eugenol mempunyai hidrogen yang terikat pada atom oksigen mudah diserang oleh suatu basa, dalam hal ini digunakan natrium hidroksida $(\mathrm{NaOH})$ berlebih membentuk ion eugenolat, garam tersebut akan mudah larut dalam air dan mudah diserang dengan gugus pengalkilasi atau metil iodida.

Tahap berikutnya yaitu mereaksikan garam natrium eugenolat dengan agen pengalkilasi metil iodida, di mana garam natrium eugenolat dapat berperan sebagai nukleofil (Fessenden dan Fessenden, 1999).

Penambahan metil iodida ke dalam campuran dilakukan secara tetes demi tetes selama satu jam karena reaksi yang terjadi bersifat eksotermis. Untuk menyempurnakan reaksi kemudian campuran direfluks selama 2 jam disertai dengan pengadukan pada kondisi refluks. Metileugenol yang dihasilkan sebanyak 7,06 g dari eugenol awal $12,15 \mathrm{~g}$ dan endemenya 53\%. Indikasi keberhasilan lainnya yaitu ditandai. dengan adanya lalat-lalat buah yang berdatangan di sekitar hasil reaksi. Hal itu terjadi karena senyawa metileugenol mempunyai aroma yang khas sebagai penarik seks bagi lalat buah, 
kemudian hasil yang diperoleh di analisis dengan infra merah dan GC-MS.

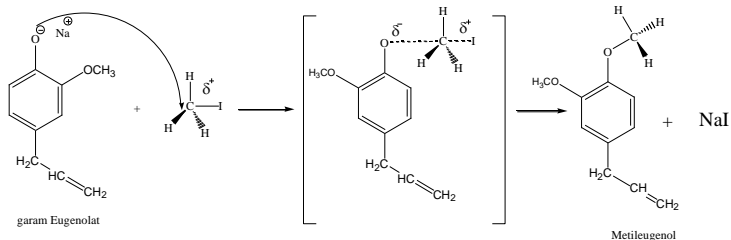

Hasil analisis dengan kromatografi gas diperoleh kromatogram hasil metileugenol dengan kemurnian $100 \%$ dengan hanya dihasilkan satu puncak pada $R_{t}=9,333$ menit.

Tahap analisis selanjutnya yaitu penentuan struktur senyawa hasil sintesis metileugenol menggunakan spektrometer inframerah (IR) dan spektrometer massa. Hasil analisis dengan spektrometer inframerah terhadap metileugenol terlihat pada gambar 1. Gambar spektrum di atas menunjukkan pita serapan yang kuat pada daerah 3100-3000 $\mathrm{cm}^{-1}$ merupakan rentangan $\mathrm{C}_{\mathrm{sp}}{ }^{2}-\mathrm{H}$ dan daerah 3000-2800 $\mathrm{cm}^{-1}$ merupakan rentangan $\mathrm{C}_{\mathrm{sp}}{ }^{3}-\mathrm{H}$, diperkuat adanya pita serapan pada daerah $1417,6 \mathrm{~cm}^{-1}$ yang menunjukkan adanya gugus metilen $\left(-\mathrm{CH}_{2}-\right)$ dan pita serapan daerah $1340 \mathrm{~cm}^{-1}$ menunjukkan adanya gugus metil $\left(-\mathrm{CH}_{3}\right)$.

Pita serapan pada daerah $1589,2 \mathrm{~cm}^{-1}$ dan 1517,9 $\mathrm{cm}^{-1}$ menunjukkan ikatan rangkap $\mathrm{C}=\mathrm{C}$ dari aromatis, diperkuat dengan serapan pada daerah $900 \mathrm{~cm}^{-1}$ yang menunjukkan gugus substituen aromatis.

Pita serapan pada daerah $1636,4 \mathrm{~cm}^{-1}$ yang diperkuat pita serapan pada daerah $995,2 \mathrm{~cm}^{-1}$ menunjukkan vibrasi ikatan $-\mathrm{CH}=\mathrm{CH}_{2}$. Sedangkan munculnya pita serapan pada daerah $1300-1200 \mathrm{~cm}^{-1}$ menunjukkan adanya gugus eter (C-O-C). Jadi dapat disimpulkan senyawa yang dianalisis mengandung gugus aromatis, gugus alkil, gugus vinil dan gugus eter, dari data tersebut merupakan gugus yang dimiliki oleh metileugenol, sehingga hasil metilasi eugenol merupakan metileugenol.

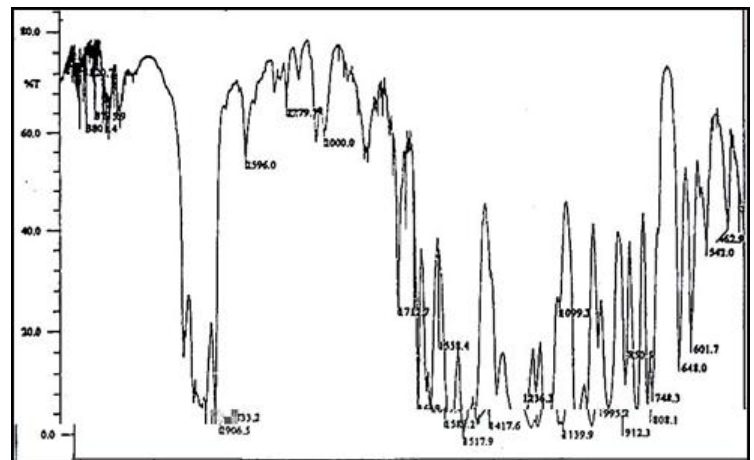

Gambar 1. Spektogram IR metileugenol

Untuk memperkuat data dan hasil dilakukan analisis dengan kromatografi gas-spektrometer massa (GC-MS) yang ditampilkan pada gambar 2. Hasil spektroskopi massa diperoleh base peak $\mathrm{m} / \mathrm{z}=178$, yang merupakan puncak dasar dari metileugenol.

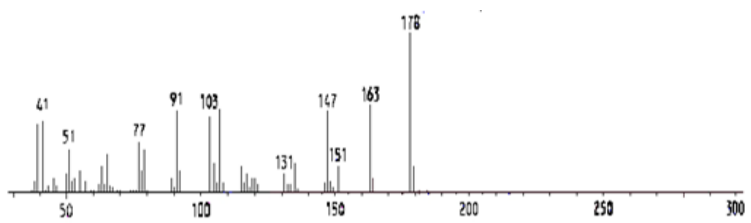

Gambar 2. Spektogram metileugenol

Puncak tersebut dapat mengalami fragmentasi sebagai berikut:

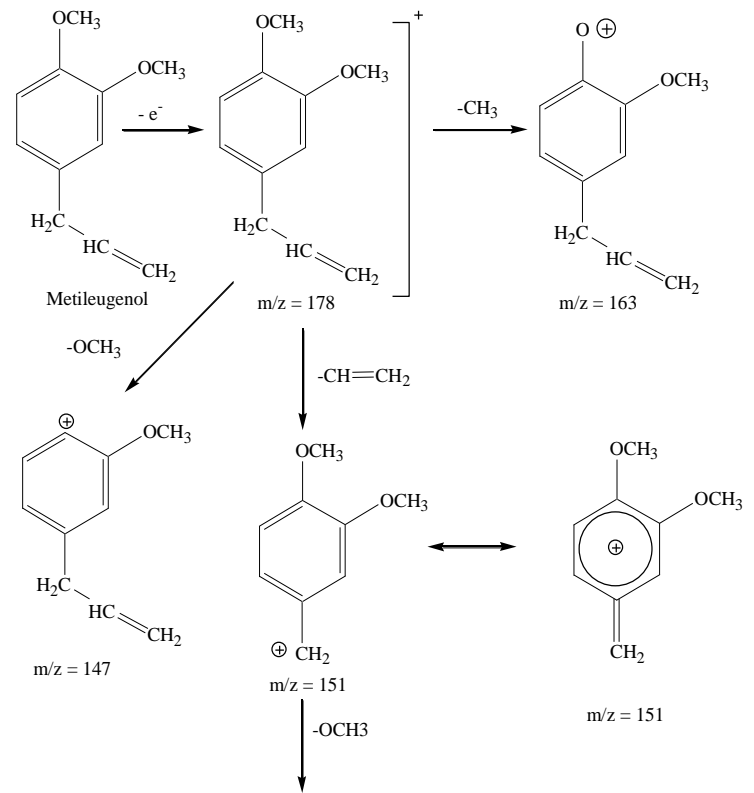




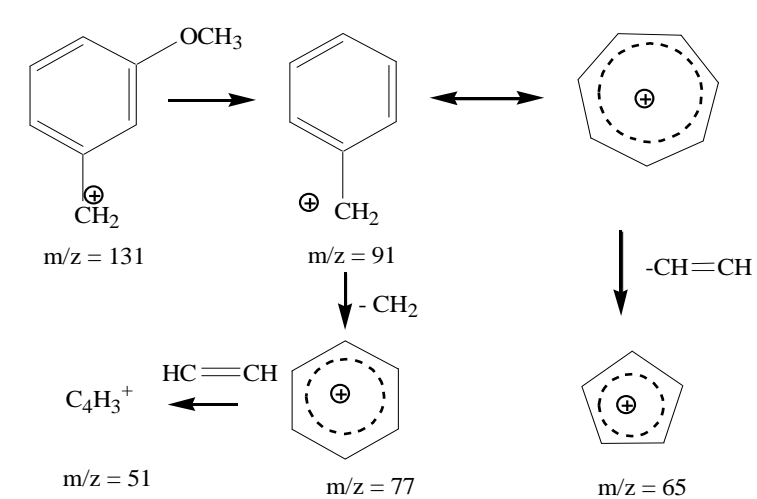

2. Sintesis Benzileugenol

Sintesis benzileugenol prinsip kerjanya sama dengan pembentukan metileugenol yang sudah diuraikan di atas. Eugenol dibentuk garam natrium eugenolat dengan mereaksikan eugenol dan $\mathrm{NaOH}$ berlebih. Tahap berikutnya yaitu mereaksikan garam natrium eugenolat dengan agen pengalkilasi benzil klorida. Penambahan benzil klorida ke dalam campuran dilakukan secara tetes demi tetes selama satu jam karena reaksi yang terjadi bersifat eksotermis. Untuk menyempurnakan reaksi campuran direfluks selama 2 jam disertai dengan pengadukan pada kondisi refluks. Hasil reaksi diperoleh campuran benzileugenol dalam lapisan atas dan air serta natrium eugenolat sisa dalam lapisan bawah.

Reaksi yang terbentuk yaitu:

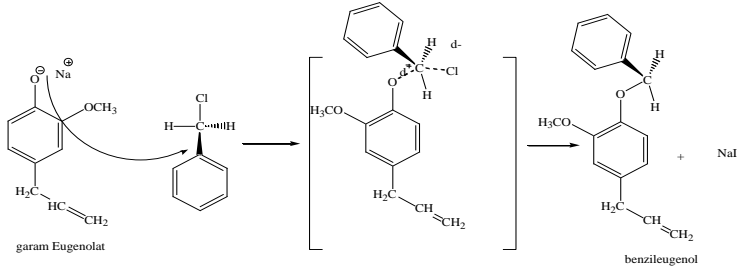

Hasil refluks kemudian didinginkan dan ditambah dengan aquades untuk melarutkan garam natrium eugenolat dan natrium hidroksida $(\mathrm{NaOH})$ yang masih tersisa sehingga terpisah dari hasil yang terbentuk karena benzileugenol tidak dapat larut dalam aquades. Pada tahap tersebut terbentuk dua lapisan, lapisan bawah (fraksi air) dan lapisan atas (fraksi organik/fraksi benzileugenol). Untuk mengambil sisa fraksi organik yang masih terbawa dalam fase air digunakan eter, kemudian hasil ekstraksi pada fraksi eter digabung dengan fraksi benzileugenol yang terbentuk tadi. Untuk menghilangkan eugenol yang tidak bereaksi digunakan natrium hidroksida $(\mathrm{NaOH}) \quad 10 \%$ sehingga akan membentuk garam natrium eugenolat dan larut dalam fraksi air, kemudian lapisan eter dicuci dengan aquades hingga netral guna menghilangkan basa atau natrium hidroksida $(\mathrm{NaOH})$ yang masih tersisa dan hasilnya dikeringkan dengan $\mathrm{Na}_{2} \mathrm{SO}_{4}$ anhidrat untuk membebaskan benzileugenol dari air. Agar diperoleh hasil benzileugenol yang murni maka pelarut eter dipisahkan/diuapkan dengan evaporator putar.

Hasil yang diperoleh berupa cairan coklat tua agak keruh dengan rendemen $47 \%$ (5,85 g) dan dianalisis dengan spektrometri infra merah dan GC-MS. Dari data GC-MS didapat kromatogram sebagai berikut:

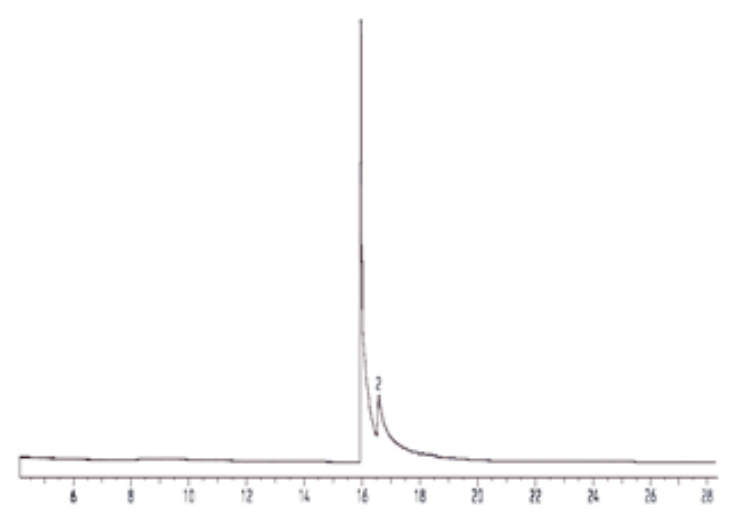

Gambar 3. Kromatogram Benzileugenol

Penentuan struktur dengan menggunakan spektrometer inframerah (IR) terhadap sintesis benzileugenol dapat disajikan pada Gambar 4.

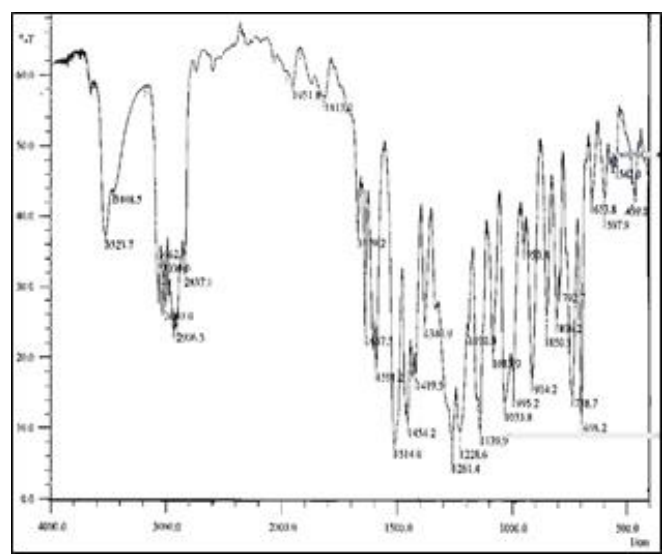

Gambar 4. Spektogram IR benzileugenol 
Gambar spectrum di atas menunjukkan pitat pada daerah 3062,7-3003,0 $\mathrm{cm}^{-1}$ merupakan rentangan $\mathrm{C}_{\mathrm{sp}}{ }^{2}-\mathrm{H}$ dan daerah 2906,5-2837,1 cm${ }^{1}$ merupakan rentangan $\mathrm{C}_{\mathrm{sp}}{ }^{3}-\mathrm{H}$, diperkuat adanya pita serapan pada daerah $1419,5 \mathrm{~cm}^{-1}$ yang menunjukkan adanya gugus metilen $\left(-\mathrm{CH}_{2}-\right)$ dan pita serapan daerah $1380,9 \mathrm{~cm}^{-1}$ menunjukkan adanya gugus metil $\left(-\mathrm{CH}_{3}\right)$. Pita serapan pada daerah $1670,2-1637,0 \mathrm{~cm}^{-1}$ yang diperkuat pita serapan pada daerah 1033,5-995,2 $\mathrm{cm}^{-1}$ menunjukkan vibrasi ikatan $-\mathrm{CH}=\mathrm{CH}_{2}$. Pita serapan pada daerah $1670,2 \mathrm{~cm}^{-1}$ dan $1514,2 \mathrm{~cm}^{-}$ 1 menunjukkan ikatan rangkap $\mathrm{C}=\mathrm{C}$ dari aromatis, diperkuat dengan serapan pada daerah $900 \mathrm{~cm}^{-1}$ yang menunjukkan gugus substituen aromatis. Sedangkan munculnya pita serapan pada daerah 1300-1200 $\mathrm{cm}^{-1}$ menunjukkan adanya gugus eter (C-O-C). Jadi dapat disimpulkan senyawa yang dianalisis mengandung gugus aromatis, gugus alkil, gugus vinil dan gugus eter, tersebut merupakan gugus yang dimiliki oleh benzileugenol, sehingga hasil sintesis merupakan benzileugenol.

Untuk memperkuat data dan hasil dilakukan analisis dengan kromatografi gas-spektrometer massa (GC-MS) dengan diperoleh base peak $\mathrm{m} / \mathrm{z}$ $=254$, yang merupakan puncak dasar dari benzileugenol. Data kromatogram menunjukkan dua puncak dapat dinyatakan salah satunya merupakan pengotor, hal itu di perkuat dengan munculnya pita serapan pada daerah $3523,7 \mathrm{~cm}^{-}$ ${ }^{1}$ sampai $3448,5 \mathrm{~cm}^{-1}$ yang merupakan daerah serapan dari alkohol. Jadi dimungkinkan masih adanya pengotor atau eugenol yang masih tersisa dalam larutan hasil.

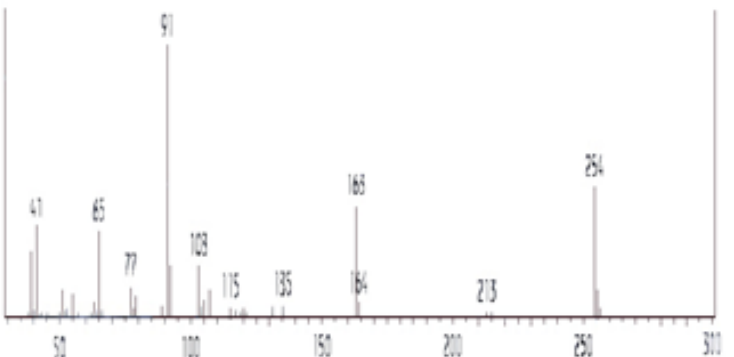

Gambar 5. Spektogram Benzileugenol
Analisis spektrometer massa seperti terlihat pada gambar di atas terlihat dua puncak di mana pada puncak 1 mempunyai puncak dasar (base peak) $\mathrm{m} / \mathrm{z}=254$, sedangkan terbentuknya dua puncak diakibatkan oleh pengotor yang masih tersisa dalam larutan hasil, hal itu diperkuat adanya gugus $\mathrm{OH}$ pada analisis dengan spektrometer IR.puncak dengan $\mathrm{m} / \mathrm{z}=254$ selanjutnya mengalami fragmentasi sebagai berikut:

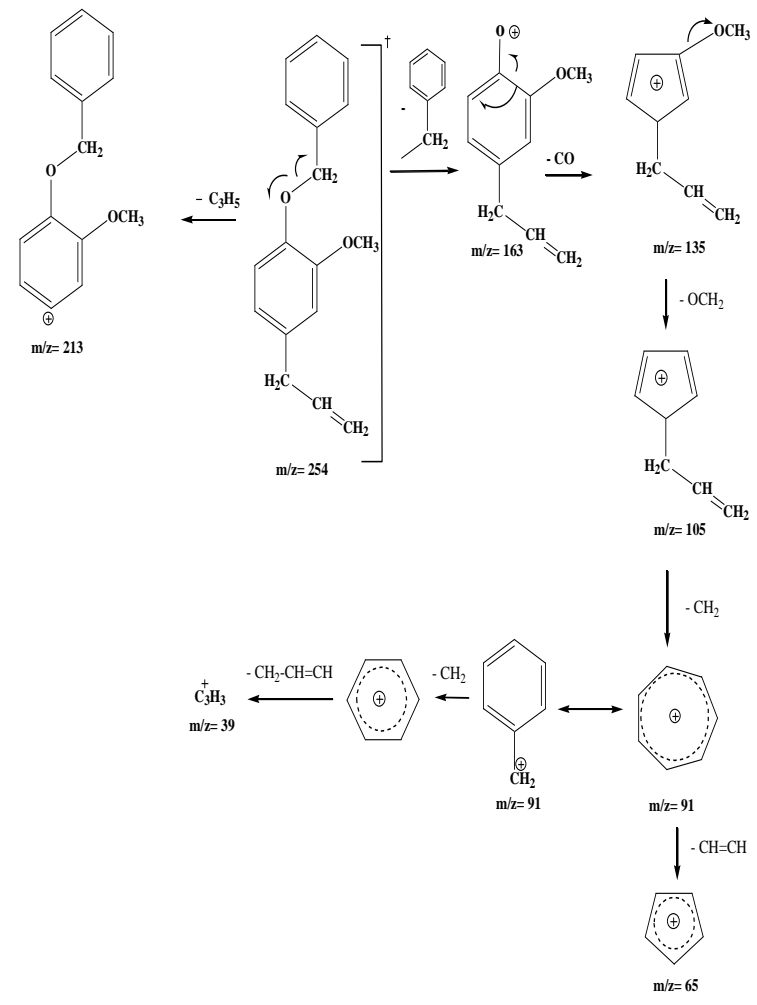

\section{KESIMPULAN}

Berdasarkan hasil penelitian dan pembahasan dapat disimpulkan sebagai berikut:

1. Hasil alkilasi terhadap eugenol diperoleh metileugenol dan benzileugenol dengan rendemen masing-masing $53 \%$ dan $47 \%$.

2. Pada analisis spektra IR dan GC-MS diperoleh spektra yang menunjukkan senyawa tersebut adalah metileugenol dan benzileugenol.

\section{DAFTAR PUSTAKA}

Agusta, A., 2000, Minyak Atsiri Tumbuhan Tropika Indonesia, Bandung: Penerbit ITB, hal. 35 . 
Anonim., 1986, Petunjuk Bercocok Tanam Cengkeh, Yogyakarta: Penerbit Kanisius, hal. 27.

Anwar, C., 1994, The Conversion of Eugenolin to more Valuable Substanses, Desertasi, Faculty of Mathematics and Natural Sciense in Gadjah Mada University, Yogyakarta, hal. 10-14.

Austin, G.T., 1987, Shreve's Chemical Process Industries, $5^{\text {nd }}$ edition, New York: Mc GrawHill Book Company, pp. 649-672.

Fessenden, J., dan Fessenden, J., 1997, Dasardasar Kimia Organik, Jakarta: Penerbit Binarupa Aksara, hal. 342-346.

Guenther, E., 1990, Minyak Atsiri, 1990, Jilid IV B, Jakarta: Penerbit UI Press, hal. 449-494.

Harold, H., 1987, Organic Chemistry, $7^{\text {nd }}$ ed, U.S.A: Houghton Mifflin Company, hal. 220.

Ketaren, S., 1985, Pengantar Teknologi Minyak Atsiri, 1985, Jakarta: Penerbit Balai Pustaka, hal. 277-284.

Mc Murry, J., 1988, Organic Chemistry, $2^{\text {nd }}$ ed, California: Brook/Cote Pub. Co.

Morrison, R. J., and Boyd, R. N., 1987, Organic Chemistry, $5^{\text {th }}$. ed., Allyn and Bacon, Inc. Toronto, hal. 703-704.

Ngadiwiyana., $\quad 2000, \quad$ Dimerisasi Metilisoeugenol dengan Katalis $\mathrm{HCl}$ dan
Hidrasi Metilisoeugenol dengan Metode $O M-D M$, Tesis Pasca Sarjana UGM, Yogyakarta, hal. 15-21.

Purwono, W. Anwar, C., Fitriani, D., dan Anggraini, I., 2003, Gama Sains, V, (1), 5563.

Sastrohamidjojo, H., 2002, Buku Ajar Kimia Minyak atsiri, Yogyakarta: F.MIPA UGM, hal. 139-141.

Sastrohamidjojo, H., 2001, Spektroskopi, Cetakan kedua, Yogyakarta: Liberty, hal. 139-141.

Sohilait, H.J., 2002, Sigma, V, (2), 35-139.

Solomons, Graham, T. W., 1982, Organic Chemistry, $4^{\text {th }}$. ed., John Wiley \& Sons, New York, hal. 649-672.

Sujadi., 1998, Metode Pemisahan, Yogyakarta: Penerbit UGM Press, 32-50.

Sykes, P., 1989, Penuntun Mekanisme Reaksi Kimia Organik, Edisi ke enam, Jakarta: Penerbit PT Gramedia, hal. 39-40.

Tan, H.K., 1991, Bulletin of Entomological Research,, 72, 709-716.

Vargas, R.I., Stark, J.D., Kido, M.H., Ketter, H.D., and Whitehand, L.C., 2000, J Econ Entomol, 93, (1), 81-87.

Windolz., 1976, The Merck Index, $9^{\text {nd }}$ ed, New york: Merck and Co. 